\title{
Role of screening in managing osteoporosis in men
}

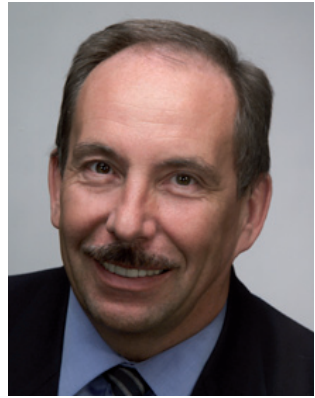

W P Olszynski University of Saskatchewan, Suite 103, 39-23rd Street East, Saskatoon, S7K OH6, Canada Tel.: + 13062442277 ; Fax: +1 3062446755 ; E-mail: olszynski@ webstersk.ca

\author{
'...men suffer comparable \\ fracture-related morbidity and \\ approximately double the \\ fracture-related mortality \\ compared with women.'
}

The role of screening in managing osteoporosis is a contentious issue for women, let alone for men. While screening is unarguably important for identifying those individuals at greatest risk for fracture, and in identifying those who will respond favorably to therapy, the reality remains that universal screening is cost-prohibitive at best and dangerous at worst. The cost of screening includes the technicians' and physicians' assessments, screening equipment and patients' loss of work, among others. Furthermore, there are possible harms of screening, including false reassurance from false-negative findings, and anxiety, decreased physical activity or inappropriate drug treatment with false-positive results. The balancing act with screening involves assessing enough individuals to identify those at greatest risk of fracture who will respond to therapy while minimizing the number needed to screen. To achieve this balance we need both sensitive and specific screening tests.

Osteoporosis in men is under-diagnosed and under-treated [1,2]. A 60-year-old white man has an approximate $25 \%$ chance of suffering a fragility fracture in his remaining lifespan [3]. Furthermore, men suffer comparable fracturerelated morbidity and approximately double the fracture-related mortality compared with women $[1,4]$, underscoring the need for screening in men.

Owing to the limited number of trials involving men and osteoporosis, and to the heterogeneity within existing studies, there is little conclusive evidence for the development of screening recommendations for the management of osteoporosis in men compared with that of postmenopausal women, a population that, while being the best understood for screening purposes, has algorithms that are still far from optimal.
The utility of bone mineral density (BMD) for osteoporosis screening is best established in white, postmenopausal women. T-scores have been developed for use in this population and have been associated with stratified risks of fracture and treatment thresholds. Numerous trials have shown that BMD prospectively predicts fractures in untreated postmenopausal women [5], and in postmenopausal women with low hip or spine BMD there are several proven therapy options for significantly decreasing fragility fracture risk [6-12]. Pharmacologic treatment of men with low BMD has also been demonstrated to significantly decrease fracture risk [13].

However, the use of BMD alone does not identify all women or men who will eventually suffer a fragility fracture [14,15]. In fact, the majority of women who do suffer a fragility fracture do not have a BMD that would be considered osteoporotic [14]. There is no doubt that a lower BMD is associated with a greater risk of fracture; however, this data conclusively demonstrates that BMD is only one of several important clinical risk factors for fracture. While there is no direct evidence to guide us, these epidemiological findings in women can almost certainly be extended to men.

'... it is imperative that if we develop

better tools for the identification of those

at risk, we should also make sure we

follow through once we find them.'

The recent American Medical Association (AMA) guidelines provide some much-needed direction for osteoporosis screening in men $[16,17]$. The authors conducted a far-reaching systematic review and grouped risk factors for low BMD and fractures in men as low, moderate or high risk [16]. Those at high risk were recommended to receive a BMD assessment that would be used with the information from the clinical risk factors. High-risk factors for fragility fracture in men included age greater than 70 years, a low body mass index (BMI; $<20$ to $25 \mathrm{~m} / \mathrm{kg}^{2}$ ), weight loss ( $>10 \%$ from baseline) and physical inactivity. Use of high-dose, systemic glucocorticoids and androgen-deprivation therapy 
were associated with moderate-to-strong risks of fracture. There was a moderate risk of smoking in men, which is likely to be a risk factor for fracture. A family history of low BMD and/or fracture was a moderate risk factor for fracture, and alcohol, when consumed in more than 3-4 drinks per day, was a significant risk factor for fracture.

As far as screening tools were concerned, the AMA reported that calcaneal ultrasound was an independent predictor of fractures in men; however, those identified by ultrasound were not always the same individuals identified as at-risk by dual-energy $\mathrm{x}$-ray absorptiometry (DEXA). The essential question remains whether those identified by ultrasound as at-risk would benefit from antifracture therapy, as all trials with antifracture therapies have focused on cohorts of men who were selected for low BMD at baseline; this limitation likely holds true for all nonDEXA clinical factors. Surprisingly, the Osteoporosis Screening Tool, which incorporates just age and weight, performed as well as calcaneal ultrasound in diagnosing DEXA-determined osteoporosis in men.

'The FRAX algorithm will hopefully shed light on important risk factors to consider when screening for osteoporosis in both men and women.'

The recently-released WHO fracture-risk algorithm (FRAX) is a multivariate model that incorporates clinical risk factors to determine an individual's absolute risk of fracture over 10 years. The risk factors included in the model were: age, sex, previous fracture, femoral neck BMD, BMI, past use of high-dose glucocorticoids, history of rheumatoid arthritis, parental history of hip fracture, current cigarette smoking and current alcohol intake. The FRAX model was developed from nine of the world's largest prospective population-based cohort studies on osteoporosis, in which approximately 15,000 men had data represented in the analyses. The FRAX algorithm will hopefully shed light on important risk factors to consider when screening for osteoporosis in both men and women; the risk calculator is available online [101]. Further validation of this tool in men is needed.

The Male Osteoporosis Risk Estimation Score (MORES), based on data from the NHANES III survey, incorporated information regarding age, weight and history of chronic obstructive pulmonary disease to help identify men at risk for osteoporosis and subsequent hip fracture who may benefit from DEXA assessment [18]. The MORES accurately predicted men who were at risk for hip fracture with an overall number needed to screen of 279 US men to prevent one hip fracture.

\section{'...if falls could be prevented, it is likely that so too could the majority of nonvertebral fragility fractures.'}

New data from the Canadian Multicentre Osteoporosis Study has highlighted that a significant decrease in hip BMD occurs in men after 65 years of age [19], suggesting that screening after 65 years may be considered to assess those at elevated risk for hip fracture.

Schousboe et al. reported that for men over the age of 80 years, universal screening would be cost effective if society was willing to accept a cost of US\$50,000 per quality adjusted life year [20]. If a man had a prior fragility fracture then it became cost effective at 65 years or older. The assumptions included 5-year use of antiresorptive therapy in those with a femoral neck BMD T-score of less than -2.5 .

Not to be forgotten are nonskeletal factors that significantly increase the probability of experiencing a fracture, and that are not included in currently available screening tools for men, but merit consideration. Perhaps the most important nonskeletal factor is that of an increased risk of falling. In one investigation, approximately $89 \%$ of men who suffered a hip fracture did so from falling from a standing height [1]; if falls could be prevented, it is likely that so too could the majority of nonvertebral fragility fractures. An increased risk of falling has been associated with numerous medications, muscle weakness, poor balance and poor eyesight [21-23].

Some of the greatest limitations include a lack of data that would guide us to recommend men with risk factors other than low BMD for success with antifracture medications, and that the evidence for the use of BMD for screening in men and non-white women is also limited. Furthermore, there is a lack of access to DEXA in many communities, and, so far, other diagnostic modalities commonly in use have not provided sufficient proof of their screening ability to be adopted into widespread use.

In the end, despite the large number of osteoporosis screening guidelines that have been disseminated, very few women and men are screened for osteoporosis and risk of fragility 


\section{Role of screening in managing osteoporosis in men - EDITORIAL}

fracture. A testament to the lack of awareness in the diagnosis and treatment of osteoporosis is perhaps best exemplified by the group of patients who may possess both one of the most robust and easily identifiable significant risk factors for future fragility fracture: a personal history of fragility fracture [24]. Fewer than $20 \%$ of women who suffer a fragility fracture are diagnosed as osteoporotic and receive antifracture treatment [25]. Of men who suffered an osteoporotic fracture of the hip, only $4.5 \%$ had treatment for osteoporosis at the time of hospital discharge [1], and after $1-5$ years of follow-up only $27 \%$ of men were administered antifracture therapy. These patients may represent those at greatest need for diagnosis and therapy and, at best, one in four is provided treatment.
While we are fortunate to now have better screening tools to assist in identifying osteoporosis and fragility fracture risk in men, we can not forget that many of our worst cases still go untreated. Therefore, it is imperative that as we develop better tools for the identification of those at risk, we also make sure we follow through once we find them.

\section{Financial \& competing interests disclosure}

The author has no relevant affiliations or financial involvement with any organization or entity with a financial interest in or financial conflict with the subject matter or materials discussed in the manuscript. This includes employment, consultancies, honoraria, stock ownership or options, expert testimony, grants or patents received or pending, or royalties.

No writing assistance was utilized in the production of this manuscript.

\section{Bibliography}

1. Kiebzak GM, Beinart GA, Perser K, Ambrose CG, Siff SJ, Heggeness MH: Undertreatment of osteoporosis in men with hip fracture. Arch. Intern. Med. 162(19), 2217-2222 (2002).

2. Morris CA, Cabral D, Cheng H et al:: Patterns of bone mineral density testing: current guidelines, testing rates, and interventions. J. Gen. Intern. Med. 19(7), 783-790 (2004).

3. Nguyen TV, Eisman JA, Kelly PJ, Sambrook PN: Risk factors for osteoporotic fractures in elderly men. Am. J. Epidemiol. 144(3), 255-263 (1996).

4. Fransen M, Woodward M, Norton R, Robinson E, Butler M, Campbell AJ: Excess mortality or institutionalization after hip fracture: men are at greater risk than women. J. Am. Geriatr. Soc. 50(4), 685-690 (2002).

5. Johnell O, Kanis JA, Oden A et al:: Predictive value of BMD for hip and other fractures. J. Bone Miner. Res. 20(7), 1185-1194 (2005).

6. Neer RM, Arnaud CD, Zanchetta JR et al.: Effect of parathyroid hormone (1-34) on fractures and bone mineral density in postmenopausal women with osteoporosis. N. Engl. J. Med. 344(19), 1434-1441 (2001).

7. Black DM, Cummings SR, Karpf DB et al: Randomised trial of effect of alendronate on risk of fracture in women with existing vertebral fractures. Fracture Intervention Trial Research Group. Lancet 348(9041), 1535-1541 (1996).

8. Black DM, Delmas PD, Eastell R et al:: Once-yearly zoledronic acid for treatment of postmenopausal osteoporosis. N. Engl. J. Med. 356(18), 1809-1822 (2007).

9. Cummings SR, Black DM, Thompson DE et al: : Effect of alendronate on risk of fracture in women with low bone density but without vertebral fractures: results from the Fracture Intervention Trial. JAMA 280(24), 2077-2082 (1998).

10. Meunier PJ, Roux C, Seeman E et al:: The effects of strontium ranelate on the risk of vertebral fracture in women with postmenopausal osteoporosis. N. Engl. J. Med. 350(5), 459-468 (2004).

11. Lyles KW, Colon-Emeric CS, Magaziner JS et al: Zoledronic acid in reducing clinical fracture and mortality after hip fracture. N. Engl. J. Med. 357, nihpa40967 (2007).

12. McClung MR, Geusens P, Miller PD et al:: Effect of risedronate on the risk of hip fracture in elderly women. Hip Intervention Program Study Group. N. Engl. J. Med. 344(5), 333-340 (2001).

13. MacLean C, Newberry S, Maglione M et al:: Systematic review: comparative effectiveness of treatments to prevent fractures in men and women with low bone density or osteoporosis. Ann. Intern. Med. 148(3), 197-213 (2008).

14. Siris ES, Chen YT, Abbott TA et al:: Bone mineral density thresholds for pharmacological intervention to prevent fractures. Arch. Intern. Med. 164(10), 1108-1112 (2004).

15. Schuit SC, van der KM, Weel AE et al: Fracture incidence and association with bone mineral density in elderly men and women: the Rotterdam Study. Bone 34(1), 195-202 (2004).

16. Liu H, Paige NM, Goldzweig CL et al: Screening for osteoporosis in men: a systematic review for an American College of Physicians guideline. Ann. Intern. Med. 148(9), 685-701 (2008).

17. Qaseem A, Snow V, Shekelle P, Hopkins R Jr, Forciea MA, Owens DK: Screening for osteoporosis in men: a clinical practice guideline from the American College of Physicians. Ann. Intern. Med. 148(9), 680-684 (2008).

18. Shepherd AJ, Cass AR, Carlson CA, Ray L: Development and internal validation of the male osteoporosis risk estimation score. Ann. Fam. Med. 5(6), 540-546 (2007).

19. Berger C, Langsetmo L, Joseph L et al:: Change in bone mineral density as a function of age in women and men and association with the use of antiresorptive agents. Can. Med. Asso. J. 178(13), 1660-1668 (2008).

20. Schousboe JT, Taylor BC, Fink HA et al: Cost-effectiveness of bone densitometry followed by treatment of osteoporosis in older men. JAMA 298(6), 629-637 (2007).

21. Kulmala J, Sihvonen S, Kallinen M, Alen M, Kiviranta I, Sipila S: Balance confidence and functional balance in relation to falls in older persons with hip fracture history. J. Geriatr. Phys. Ther. 30(3), 114-120 (2007).

22. Hartikainen S, Lonnroos E, Louhivuori K: Medication as a risk factor for falls: critical systematic review. J. Gerontol. A Biol. Sci. Med. Sci. 62(10), 1172-1181 (2007).

23. van Helden S, Wyers CE, Dagnelie PC et al: Risk of falling in patients with a recent fracture. BMC Musculoskelet. Disord. 8, 55 (2007).

24. Kanis JA, Johnell O, De Laet C et al:: A meta-analysis of previous fracture and subsequent fracture risk. Bone 35(2), 375-382 (2004).

25. Bessette L, Ste-Marie LG, Jean S et al: The care gap in diagnosis and treatment of women with a fragility fracture. Osteoporos. Int. 19(1), 79-86 (2008).

\section{Website}

101. WHO Fracture Risk Assessment Tool www.shef.ac.uk/FRAX 